\begin{tabular}{lcccr} 
T H E & A R C H I V E & O F & M E C H A N I C A L & E N G I N E E R I N G \\
\hline VOL. LX & 2013 & Number 2
\end{tabular}

10.2478/meceng-2013-0016

Key words: Hydrodynamic Bearings; Hydrodynamic Friction; Hydrodynamic Lubrication; Load-Carrying Capacity; Rabinowitsch Fluid Model; VI Improvers

\title{
APPLICATION OF RABINOWITSCH FLUID MODEL TO PIVOTED CURVED SLIDER BEARINGS
}

\begin{abstract}
In the present theoretical analysis, the combined effects of slider curvature and non-Newtonian pseudoplastic and dilatant lubricants (lubricant blended with viscosity index improver) on the steady and dynamic characteristics of pivoted curved slider bearings have been investigated for Rabinowitsch fluid model. The modified Reynolds equations have been obtained for steady and damping states of bearing. To solve the modified Reynolds equations, perturbation theory has been adopted. The results for the steady state characteristics (steady state film pressure, load carrying capacity and centre of pressure) and dynamic characteristics (dynamic damping and dynamic stiffness) have been calculated numerically for various values of viscosity index improver using Mathematica. In comparison with the Newtonian lubricants, higher values of film pressure, load carrying capacity, dynamic damping and dynamic stiffness have been obtained for dilatant lubricants, while the case was reversed for pseudoplastic lubricants. Significant variations in the bearing characteristics have been observed for even small values of pseudoplastic parameter, that is, with the non-Newtonian dilatant and pseudoplastic behaviour of the fluid.
\end{abstract}

\section{Introduction}

The requirement of high performance and long life bearings in industrial and scientific applications has increased the use of non-Newtonian lubricants. It has been shown that the addition of small amounts of long-chained polymer additives (viscosity index improvers) to a Newtonian fluid produces a desirable non-Newtonian lubricant [1]. The additives raise the viscosity index of lubricants and increase their stability by minimizing the sensitivity to the change in shearing stress with strain rate and thermal variation. These lubricants behave like pseudoplastic, dilatant and viscoelastic fluids depending on the nature and quantity of the additives. However, the most

* Department of Applied Science and Humanities, Kamala Nehru Institute of Technology, Sultanpur, U. P., India; E-mail: journals4phd@gmail.com 
of the lubricants added with commercial additives behave like pseudoplastic or dilatant lubricants, which have a considerable influence on the various performance properties of machine elements.

To study the effects of the lubricant additives on the performance and stability of the various types of hydrostatic, hydrodynamic and squeeze film bearings, many non-Newtonian fluid models such as power law, couple stress, micropolar, Herschel-Bulkley, Bingham, Powel-Eyring, Ree-Eyring, Cross and Ellis models have been adopted in theoretical investigations. However, many of these models either work for a limited range of strain rate or lack of experimental verification, for illustration, the Powell-Eyring's model fits the experimental viscosity data over the range of $10-10^{5} \mathrm{sec}^{-1}$ and the power law model fits their data only over the limited range of $10-500 \mathrm{sec}^{-1}$ [2]; Bingham plastics and Ree-Eyring models deviate from experimental data [3]; the experimental verifications for couple stress and micropolar models for bearings are still hard to find in literature. Therefore, in order to predict the performance characteristics of the bearings and thereby the machine elements accurately, a more realistic lubricant model is required for the theoretical investigation. As the Rabinowitsch fluid model fits the viscosity data over a wide range of shear rate and its experimental verification is available [4], the analysis of performance characteristics of film lubricated bearings with Rabinowitsch fluids is motivated.

In the Rabinowitsch fluid model, the following empirical stress-strain relation holds :

$$
\tau_{x y}+\kappa \tau_{x y}^{3}=\mu \frac{\partial u}{\partial y}
$$

where $\mu$ is the zero shear rate viscosity and $\kappa$ is the non-linear factor responsible for the non-Newtonian effects of the fluid which will be referred to as coefficient of pseudoplasticity in this paper. This model can be applied to Newtonian lubricants for $\kappa=0$, dilatant lubricants for $\kappa<0$, and pseudoplastic lubricants for $\kappa>0$. The experimental verification for this model was presented by Wada and Hayashi [4]. The theoretical results for film pressure, load capacity and squeezing time of journal bearing were found to be in good agreement with the experimental ones. The film pressure and load capacity for pseudoplastic lubricants was found to be smaller than those for the Newtonian fluids. Afterwards, the theoretical study of bearing performance with non-Newtonian lubricants using this and other models were done by Bourging and Gay [5] on journal bearing; Hsu and Saibel [6] and Hashmimoto and Wada [7] on circular plates bearing; Usha and Vimla [8] on squeeze film between two plane annuli and Hung[9] on infinitely wide parallel rectangular plates. Recently, Singh et al. [10-13] used this model to analyze the performance of hydrostatic thrust and squeeze film bearings. 
The dynamic analysis of the slider and other bearings has also been the centre of attention of various researchers in recent decades. In the direction of dynamic analysis of bearings in recent years, the contributions of Sharma and Pandey [14] on infinitely wide slider bearing, Gautam [15] on annular seals, Tsuchiama et. al [16] on slider bearing and Gautam et. al. [17] on short wave journal bearings are appreciable. However, none of the investigators have put up their attention to study theoretically, the problem of isothermal, incompressible laminar flow lubricant for pivoted curved slider bearings taking into account the Rabinowitsch fluid model.

In the present paper, the effect of non-Newtonian lubricants on the steady and dynamic characteristics of pivoted curved slider bearing has been investigated using Rabinowitsch fluid model. Since, the problem is of non-linear nature in its theoretical investigation, the numerical results for steady state pressure, load capacity, centre of pressure, dynamic stiffness and damping coefficients have been obtained using Mathematica.

\section{Constitutive Equations and Boundary Conditions}

The physical configuration of a curved slider bearing is shown in Figure 1 . The bearing consists of two surfaces, a plane and a curved slider, separated by a lubricant film. The plane is moving with a uniform velocity $\mathrm{U}$, as shown in the Figure 1, while the curved surface is at rest. The lubricant in the system is taken as non-Newtonian Rabinowitsch fluid. The body forces and body couples are assumed to be absent.

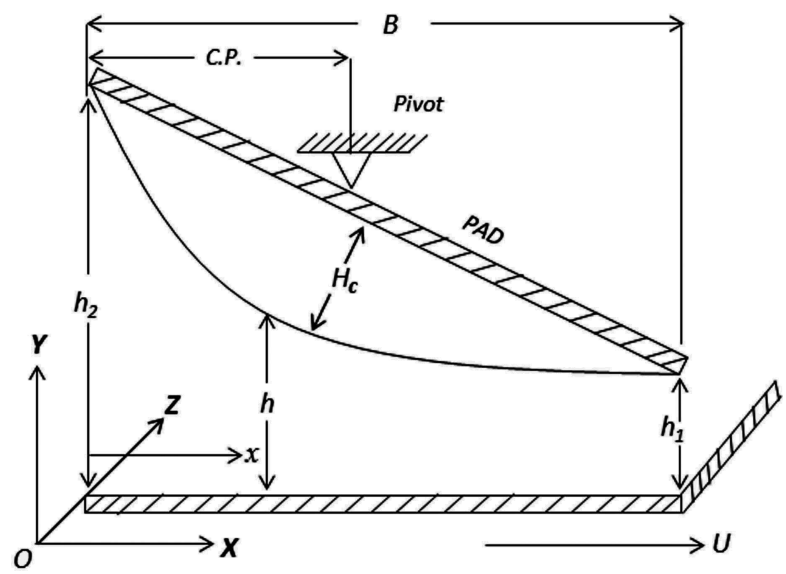

Fig. 1. Schematic diagram of curved slider bearing with a pivot at centre of pressure (C.P.). Maximum height of the curved segment is $H_{c}$

Under the assumptions of hydrodynamic lubrication applicable to thin film as considered by Pinkus and Sternlicht [18], Kapur [20] and Cameron 
[23] (Appendix), the field equations governing the motion of an incompressible non-Newtonian fluid - Rabinowitsch fluid model used by Wada and Hayashi [4] are :

$$
\begin{gathered}
\frac{\partial u}{\partial x}+\frac{\partial v}{\partial y}=0 \\
\frac{\partial p}{\partial x}=\frac{\partial \tau_{x y}}{\partial y} \\
\frac{\partial p}{\partial y}=0
\end{gathered}
$$

which are solved under the following boundary conditions :

$$
\begin{gathered}
u=U, \quad v=0 \text { at } y=0 \\
u=0 \text { at } y=h(x, t) \\
v=V=\frac{\partial h}{\partial t} \text { at } y=h(x, t) \\
p=0 \text { at } x=0, B
\end{gathered}
$$

where $u$ and $v$ are the velocity components in $x$ and $y$ directions and $h(x, t)$ is the film thickness between the bearing plates respectively.

\section{Analysis}

Integration of equation (3) with respect to y yields :

$$
\tau_{x y}=\frac{\partial p}{\partial x} y+c_{1}
$$

From equations (9) and (1), velocity gradient is obtained as :

$$
\frac{\partial u}{\partial y}=\frac{1}{\mu}\left[\left(\frac{\partial p}{\partial x} y+c_{1}\right)+\kappa\left(\frac{\partial p}{\partial x} y+c_{1}\right)^{3}\right]
$$

Integrating equation (10) under the boundary conditions $(5,6)$, velocity $u$ is obtained as :

$$
\begin{aligned}
& u=\frac{1}{\mu}\left[\frac{1}{2} \frac{\partial p}{\partial x} y(y-h)+\kappa\left(\frac{\partial p}{\partial x}\right)^{3}\left\{\frac{1}{4} y^{4}-\frac{1}{2} h y^{3}+\frac{3}{8} h^{2} y^{2}-\frac{1}{8} h^{3} y\right\}\right]+ \\
& U\left[1-\frac{y+\kappa\left(\frac{\partial p}{\partial x}\right)^{2}\left(y^{3}-\frac{3}{2} h y^{2}+\frac{3}{4} h^{2} y\right)}{h\left(1+\frac{1}{4} \kappa\left(\frac{\partial p}{\partial x}\right)^{2} h^{2}\right)}\right]
\end{aligned}
$$


Integrating the equation of continuity (2) under the boundary conditions $(5,7)$ for $v$ using (11), the modified Reynolds equation is obtained as:

$$
\frac{\partial}{\partial x}\left[h^{3} \frac{\partial p}{\partial x}+\frac{3}{20} \kappa h^{5}\left(\frac{\partial p}{\partial x}\right)^{3}\right]=6 \mu U \frac{\partial h}{\partial x}+12 \mu \frac{\partial h}{\partial t}
$$

For small-amplitude oscillations of the runner, the expression for the film thickness can be taken as:

$$
h \equiv h(x, t)=h_{s}(x)+h_{m}(t)
$$

where $h_{s}(x)$ is the steady state film thickness and $h_{m}(t)$ is the variation of minimum film thickness with the time in dynamic condition which becomes zero in steady state.

The steady state film profile is taken $[19,20]$ as

$$
h_{s}(x)=H_{c}\left[4\left(\frac{x}{B}-\frac{1}{2}\right)^{2}-1\right]+h_{1}\left[1+\left(r_{b}-1\right)\left(1-\frac{x}{B}\right)\right]
$$

where, $r_{b}=h_{2} / h_{1}$.

Introducing the dimensionless parameters

$$
\Delta=\frac{H_{c}}{h_{1}} \text { and } \bar{x}=\frac{x}{B}
$$

the dimensionless Reynolds equation becomes

$$
\frac{\partial}{\partial \bar{x}}\left[\bar{h}^{3} \frac{\partial \bar{p}}{\partial \bar{x}}+\frac{3}{20} \alpha \bar{h}^{5}\left(\frac{\partial \bar{p}}{\partial \bar{x}}\right)^{3}\right]=6 \frac{\partial \bar{h}_{s}}{\partial \bar{x}}+12 \vartheta \frac{\partial \overline{h_{m}}}{\partial \tau}
$$

where

$$
\bar{h}_{s}=\Delta\left[4\left(\bar{x}-\frac{1}{2}\right)^{2}-1\right]+\left[1+\left(r_{b}-1\right)(1-\bar{x})\right]
$$

and $\vartheta=B \omega / U$ is the damping parameter, $\omega$ is frequency of oscillation, $\alpha=\kappa \mu^{2} U^{2} / h_{1}^{2}$ is the parameter of pseudoplasticity responsible for the nonNewtonian behaviour of the lubricant. For $\alpha=0$ equation (18) becomes the classical Reynolds equation for slider bearing with Newtonian lubricant.

Assuming that the runner undergoes a small-amplitude oscillation about its steady state position, variation of the minimum film thickness $\left(\bar{h}_{m}\right)$ and the pressure $(\bar{p})$ under damping condition can be taken of the form

$$
\begin{gathered}
\bar{h}_{m}=\varepsilon e^{i \tau} \\
\bar{p}=\bar{p}_{o}+\varepsilon \bar{p}_{1} e^{i \tau}
\end{gathered}
$$


where $\bar{p}_{o}$ is the steady state pressure.

With the expressions for $h_{m}$ and $\bar{p}$ in equation (17-18), the Reynolds equation (15) can be written as

$$
\frac{\partial}{\partial \bar{x}}\left[\left(h_{s}+\varepsilon e^{i \tau}\right)^{3}\left(\bar{p}_{o}+\varepsilon \bar{p}_{1} e^{i \tau}\right)+\frac{3}{20} \alpha\left(h_{s}+\varepsilon e^{i \tau}\right)^{5}\left(\bar{p}_{o}+\varepsilon \bar{p}_{1} e^{i \tau}\right)^{3}\right]=6 \frac{\partial \bar{h}_{s}}{\partial \bar{x}}+12 \vartheta i \varepsilon \bar{p}_{1} e^{i \tau}
$$

Expanding and comparing the real and imaginary parts of equation (19), the Reynolds equation under steady state is obtained as

$$
\frac{d}{d \bar{x}}\left[\bar{h}_{s}^{3} \frac{d \bar{p}_{o}}{d \bar{x}}+\frac{3}{20} \alpha \bar{h}_{s}^{5}\left(\frac{d \bar{p}_{o}}{d \bar{x}}\right)^{3}\right]=6 \frac{d \bar{h}_{s}}{d \bar{x}}
$$

and the Reynolds equation under damping condition is obtained as

$$
\frac{d}{d \bar{x}}\left[\bar{h}_{s}^{3}\left\{1+\frac{9}{20} \alpha \bar{h}_{s}^{2}\left(\frac{d \bar{p}_{o}}{d \bar{x}}\right)^{2}\right\} \frac{d \bar{p}_{1}}{d \bar{x}}\right]=12 \vartheta i-3 \frac{d}{d \bar{x}}\left[\bar{h}_{s}^{2}\left\{\frac{d \bar{p}_{o}}{d \bar{x}}+\frac{5}{20} \alpha \bar{h}_{s}^{2}\left(\frac{d \bar{p}_{o}}{d \bar{x}}\right)^{3}\right\}\right]
$$

\section{Steady State Pressure}

Let the steady state pressure be expressed as

$$
\bar{p}_{0}(\bar{x})=\bar{p}_{00}(\bar{x})+\alpha \bar{p}_{01}(\bar{x})
$$

Using equation (22) in the steady state Reynolds equation (20), the perturbed equations are obtained as

$$
\begin{gathered}
\frac{d \bar{p}_{00}}{d \bar{x}}=\frac{6}{\bar{h}_{s}^{2}}+\frac{C_{00}}{\bar{h}_{s}^{3}} \\
\frac{d \bar{p}_{01}}{d \bar{x}}=\frac{C_{01}}{h_{s}^{3}}-\frac{3}{20} \bar{h}_{s}^{2}\left(\frac{6}{\bar{h}_{s}^{2}}+\frac{C_{00}}{\bar{h}_{s}^{3}}\right)^{3}
\end{gathered}
$$

Integrating equations (23-24) under the conditions of zero pressure at the boundaries $(\bar{x}=0,1)$, the steady state film pressure is obtained as the definite integral

$$
\bar{p}_{o}(\bar{x})=\int_{0}^{\bar{x}} \frac{C_{00}+6 \bar{h}_{s}}{\bar{h}_{s}^{3}} d \bar{x}+\alpha\left[C_{01} \int_{0}^{\bar{x}} \frac{1}{\bar{h}_{s}^{3}} d \bar{x}-\frac{3}{20} \int_{0}^{\bar{x}} \frac{\left(C_{00}+6 \bar{h}_{s}\right)^{3}}{\bar{h}_{s}^{7}} d \bar{x}\right]
$$


where

$$
C_{00}=-6 \int_{0}^{\bar{x}} \frac{1}{\bar{h}_{s}^{2}} d \bar{x} / \int_{0}^{\bar{x}} \frac{1}{\bar{h}_{s}^{3}} d \bar{x}
$$

and

$$
C_{01}=\frac{3}{20} \int_{0}^{\bar{x}} \frac{\left(C_{00}+6 \bar{h}_{s}\right)^{3}}{\bar{h}_{s}^{7}} d \bar{x} / \int_{0}^{\bar{x}} \frac{1}{\bar{h}_{s}^{3}} d \bar{x}
$$

\section{Steady-State Load Carrying Capacity}

The dimensionless load carrying capacity of the bearing can be calculated as

$$
\bar{W}=\int_{0}^{1} \bar{p}_{o} d \bar{x}
$$

In order to avoid very lengthy procedure of integration, numerical integration method (Gaussian Quadrature formula) has been adopted to obtain the numerical values of the load capacity using Mathematica. The Gaussian Quadrature formula has been adopted due to its higher rate of convergence in comparison with the other numerical methods like Trapezium Rule, Midpoint Rule and Simpson's one third and three eighth formulae.

\section{Dynamic Stiffness and Damping Characteristics}

In order to obtain the analytical solution of the dynamic stiffness coefficient $\bar{S}_{D}$ and dynamic damping coefficient $\bar{C}_{D}$, the perturbed film pressure gradient $\frac{d \bar{p}_{1}}{d \bar{x}}$ is obtained from equations (21) and (25) which is given as follows -

$$
\frac{d \bar{p}_{1}}{d \bar{x}}=\frac{C_{1}+12 \vartheta i \bar{x}-3 \bar{h}_{s}^{2}\left[f(\bar{x})+\frac{5}{20} \alpha \bar{h}_{s}^{2} f(\bar{x})^{3}\right]}{\bar{h}_{s}^{3}\left[1+\frac{9}{20} \alpha \bar{h}_{s}^{2} f(\bar{x})^{2}\right]}
$$

Further, the perturbed pressure

$$
\bar{p}_{1}(\bar{x})=\bar{p}_{11}(\bar{x})+i \vartheta \bar{p}_{12}(\bar{x})
$$

is obtained on integrating the equation (29) under the boundary conditions $\bar{p}_{1}=0$ at $\bar{x}=0,1$

where

$$
f(\bar{x})=\frac{d \bar{p}_{o}}{d \bar{x}}
$$




$$
\begin{gathered}
\bar{p}_{11}(\bar{x})=C_{11} \int_{0}^{\bar{x}}\left[\frac{1}{\bar{h}_{s}^{3}\left\{1+\frac{9}{20} \alpha \bar{h}_{s}^{2} f(\bar{x})^{2}\right\}}\right] d \bar{x}-3 \int_{0}^{\bar{x}}\left[\frac{f(\bar{x})\left\{1+\frac{5}{20} \alpha \bar{h}_{s}^{2} f(\bar{x})^{2}\right\}}{\bar{h}_{s}\left\{1+\frac{9}{20} \alpha \bar{h}_{s}^{2} f(\bar{x})^{2}\right\}}\right] d \bar{x} \\
\bar{p}_{12}(\bar{x})=C_{12} \int_{0}^{\bar{x}}\left[\frac{12}{\bar{h}_{s}^{3}\left\{1+\frac{9}{20} \alpha \bar{h}_{s}^{2} f(\bar{x})^{2}\right\}}\right] d \bar{x}+\int_{0}^{\bar{x}}\left[\frac{12 \bar{x}}{\bar{h}_{s}^{3}\left\{1+\frac{9}{20} \alpha \bar{h}_{s}^{2} f(\bar{x})^{2}\right\}}\right] d \bar{x} \\
C_{11}=\frac{3 \int_{0}^{1}\left[\frac{f(\bar{x})\left\{1+\frac{5}{20} \alpha \bar{h}_{s}^{2} f(\bar{x})^{2}\right\}}{\bar{h}_{s}\left\{1+\frac{9}{20} \alpha \bar{h}_{s}^{2} f(\bar{x})^{2}\right\}}\right] d \bar{x}}{\int_{0}^{1}\left[1 / \bar{h}_{s}^{3}\left\{1+\frac{9}{20} \alpha \bar{h}_{s}^{2} f(\bar{x})^{2}\right\}\right] d \bar{x}}
\end{gathered}
$$

and

$$
C_{12}=-\frac{\int_{0}^{1}\left[12 \bar{x} / \bar{h}_{s}^{3}\left\{1+\frac{9}{20} \alpha \bar{h}_{s}^{2} f(\bar{x})^{2}\right\}\right] d \bar{x}}{\int_{0}^{1}\left[1 / \bar{h}_{s}^{3}\left\{1+\frac{9}{20} \alpha \bar{h}_{s}^{2} f(\bar{x})^{2}\right\}\right] d \bar{x}}
$$

The film force $F_{D}$, under the damping condition is given by

$$
F_{D}=L \int_{0}^{B} p_{1}(x) d x
$$

In the dimensionless form

$$
\bar{F}_{D}=\int_{0}^{1} \bar{p}_{1}(\bar{x}) d \bar{x}
$$

The resulting dynamic force can be expressed in the terms of linearized damping and stiffness coefficient [21] as follows

$$
F_{D} \varepsilon e^{i \tau}=-S_{D} h_{1} \varepsilon e^{i \tau}-C_{D} \frac{d}{d t}\left(h_{1} \varepsilon e^{i \tau}\right)
$$

In the dimensionless form

$$
\bar{F}_{D}=-\bar{S}_{D}-i \vartheta \bar{C}_{D}
$$

From the equations (37) and (39), the dimensionless damping coefficient $\bar{C}_{D}$ and stiffness coefficient $\bar{S}_{D}$ can be found, which is

$$
\begin{gathered}
\bar{S}_{D}=-\operatorname{Re}\left(\bar{F}_{D}\right) \approx-\int_{0}^{1} \bar{p}_{11} d \bar{x} \\
\bar{C}_{D}=-\operatorname{Im}\left(\bar{F}_{D}\right) \approx-\int_{0}^{1} \bar{p}_{12 d \bar{x}}
\end{gathered}
$$




\section{Centre of Pressure}

The centre of pressure of bearing in dimensionless form can be given as

$$
\overline{\bar{x}}=\int_{0}^{1} \bar{x} \bar{p} d \bar{x} / \int_{0}^{1} \bar{p} d \bar{x}
$$

\section{Results and Discussions}

To study the non-Newtonian lubricant effects on the steady and dynamic characteristics of pivoted curved slider bearing, the numerical results for steady state pressure, load carrying capacity, centre of pressure, and coefficients of dynamic stiffness and damping characteristics have been obtained for the different values of parameter of pseudoplasticity $(\alpha)$ and parameter of slider curvature $(\Delta)$ within the valid range of convergence $[4,20]$. For a plane slider, the steady state film pressure (Fig. 2) is found to be identical with Taylor and Dowson [22] and both the steady state pressure and load capacity for non-Newtonian lubricants (Fig. 2-4) are identical with [6]. Furthermore, the Newtonian results for pressure (Fig. 2), load capacity (Fig. 3-4) and centre of pressure (Fig. 8-9) are identical with Kapur [20].

The nature of lubricant is Newtonian for the parameter of pseudoplasticity $\alpha=0$, dilatant for $\alpha<0$ and pseudoplastic for $\alpha>0$.

The bearing become plane pivoted slider for the curvature parameter $\Delta=0$. For the numerical calculation and the analysis of the various results, the values for the film thickness ratio $1.2<r_{b}<3.7$, the slider curvature parameter $0<\Delta<0.8$ [20] and the parameter of pseudoplasticity $-0.1<$ $\alpha<0.1[4,9]$ have been taken in the present analysis.

Figure 2 shows the variation of dimensionless steady state film pressure with respect to the dimensionless coordinate $\bar{x}$ for the curvature parameter $\Delta=0,0.25,0.5$ and $\alpha=-0.1,0.0,0.1$. It is observed that for each value of $\Delta$ and $\bar{x}$, the dimensionless pressure decreases as $\alpha$ increases from -0.1 to 0.1 i.e. on comparison with the Newtonian case, the dimensionless pressure decreases with the pseudoplasticity and increases with the dilatant nature of the lubricant for both the plane and curved slider bearings which agrees with the results of Wada and Hayashi [4] and Hung [9]. Further, the dimensionless pressure is lowest for the plane slider $(\Delta=0)$ and for each value of $\bar{x}$, the pressure increases as the curvature increases upto $\bar{x} \approx 0.7$ and decreases thereafter. Due to this, a shift in the peak value of pressure is observed. This establishes the validity of present analysis for Newtonian lubricants [19-20]. 


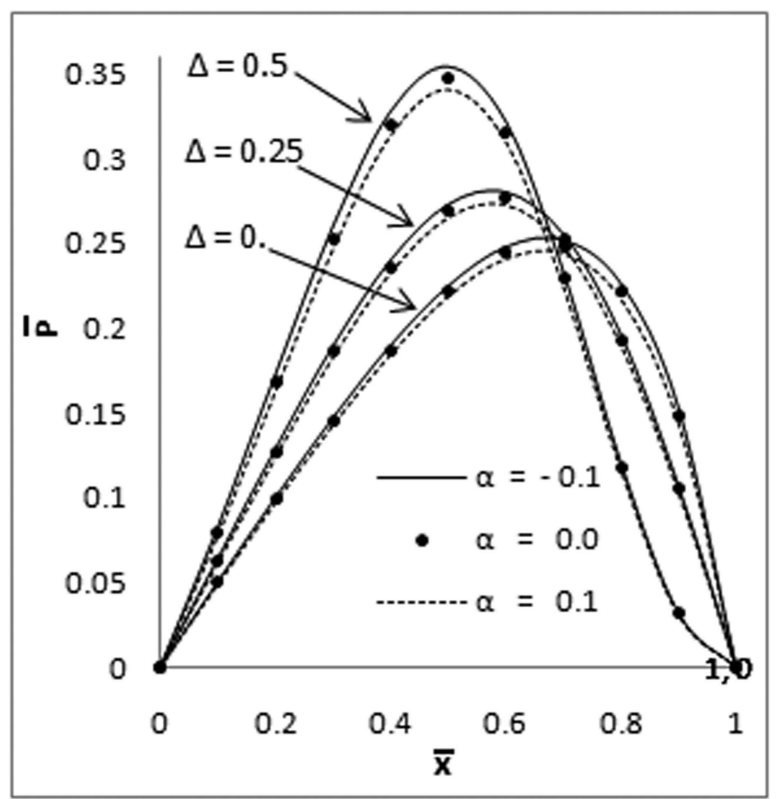

Fig. 2. Variation of dimensionless steady state film pressure $\left(\bar{p}_{o}\right)$ with dimensionless coordinate $\bar{x}$ for $r_{b}=2$. For $\Delta=0$ Newtonian results are identical with Taylor and Dowson [22] and other results are identical with Hsu and Saibel [6]

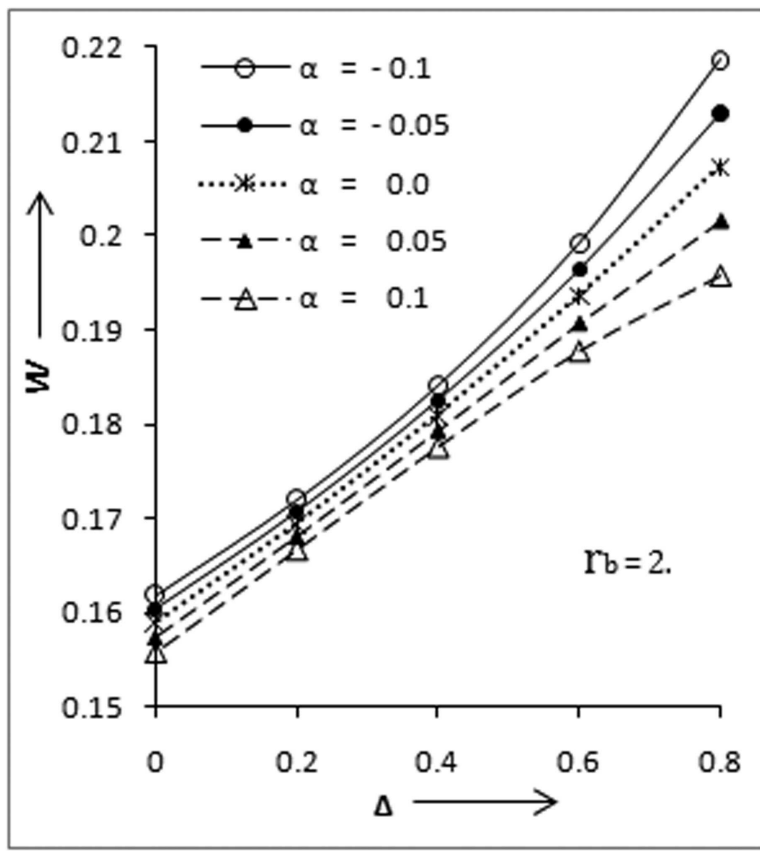

Fig. 3. Variation of dimensionless steady state load carrying capacity $(\bar{W})$ of bearing with $\Delta$ for $r_{b}=2$. Newtonian results are identical with Kapur [20], and results for $\Delta=0$ are identical with Hsu and Saibel [6] 
Figure 3 shows the variation of dimensionless steady state load carrying capacity of bearing with respect to the curvature parameter $\Delta$ with a particular value of step ratio $r_{b}=2$ and different values of pseudoplasticity parameter $\alpha$. It is observed that the dimensionless load capacity increases with the increase of curvature $\Delta$, which agrees with the results of Kapur [20] and establishes the present results for Newtonian lubricants $(\alpha=0)$. It is further observed that for each value of $\Delta$, the load carrying capacity with dilatant lubricants $(\alpha<0)$ is higher than that in the Newtonian case and it is less than Newtonian case for pseudoplastic lubricants $(\alpha>0)$, which is in agreement with real nature of the problem [4,9].

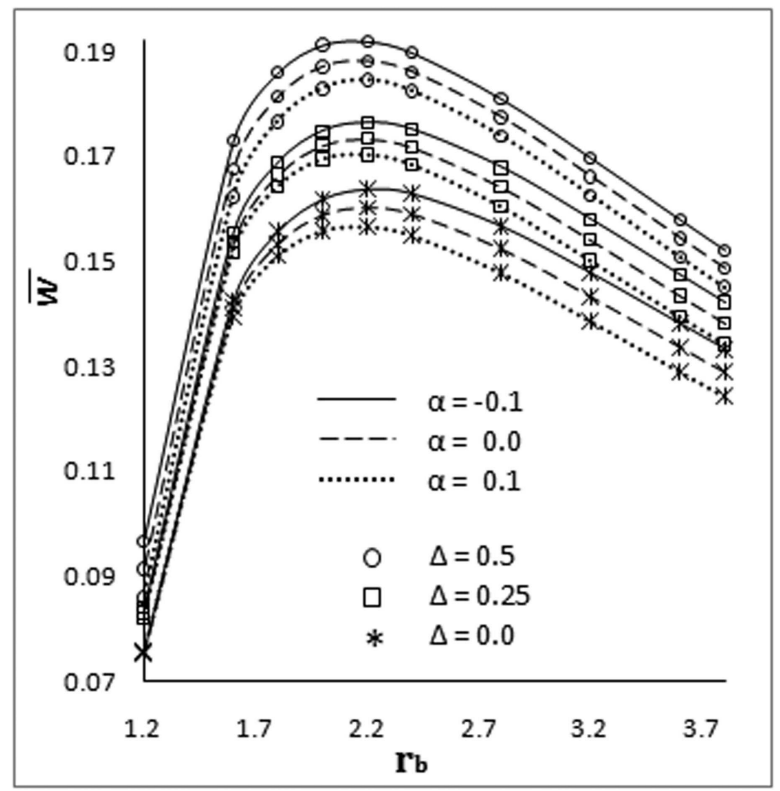

Fig. 4. Variation of dimensionless steady state load carrying capacity $(\bar{W})$ of bearing with $r_{b}$. Newtonian results are identical with Kapur [20], and results for $\Delta=0$ are all identical with Hsu and Saibel [6]

Figure 4 shows the variation of dimensionless steady state load carrying capacity of bearing with respect to the step ratio $r_{b}$ with different values of curvature parameter $\Delta$ and pseudoplasticity parameter $\alpha$. It is observed that the dimensionless load capacity increases with the increase in the step ratio $r_{b}$ upto $r_{b} \approx 2$ and decrease thereafter. It is further observed that for each value of $\Delta$ and $r_{b}$, the load carrying capacity for $\alpha=-0.1$ (dilatant lubricants) is higher than that in the Newtonian case $(\alpha=0)$ and for $\alpha=0.1$ (pseudoplastic lubricants), it is less than Newtonian case. Also, on comparison with the Newtonian case, the deviation of load capacity due to pseudoplasticity and dilatant effect is significant with $r_{b}>1.5$. 


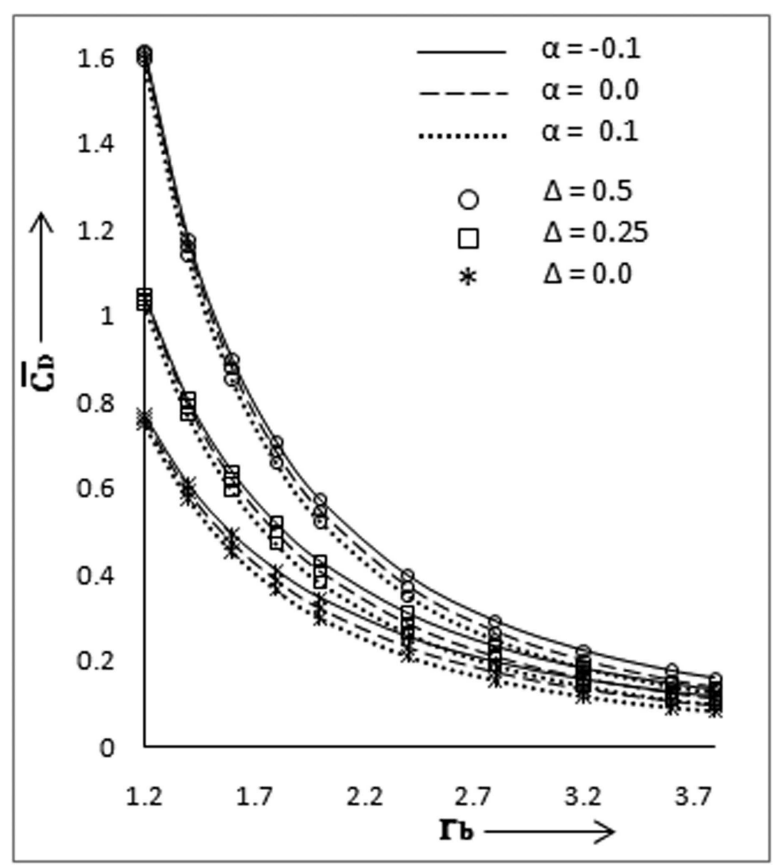

Fig. 5. Variation of dimensionless damping coefficient $\bar{C}_{D}$ with thickness ratio $r_{b}$

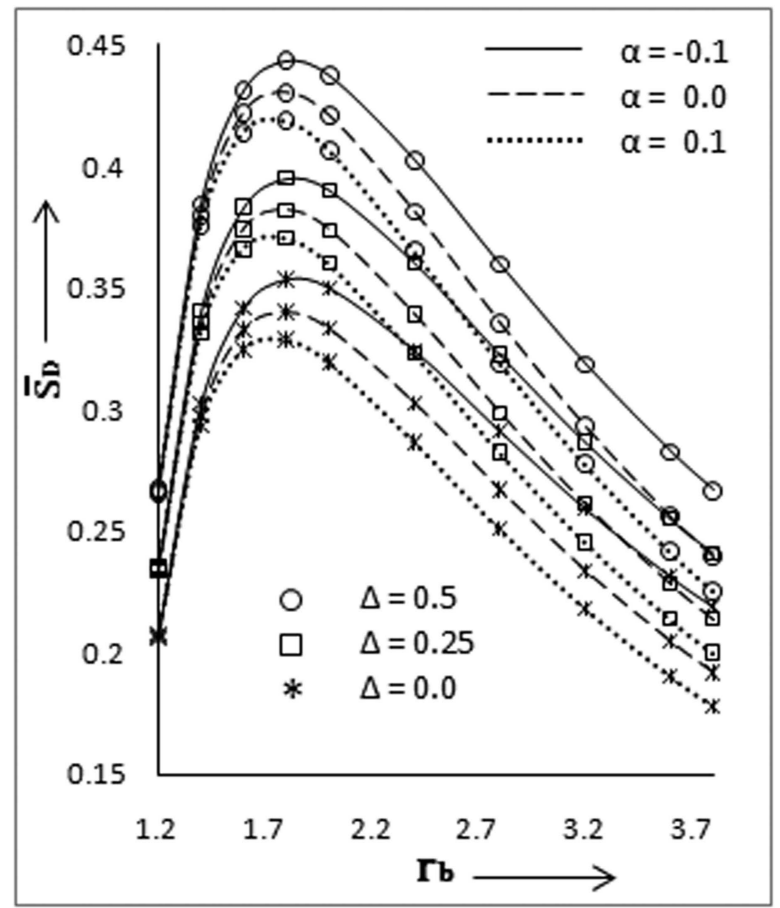

Fig. 6. Variation of dimensionless stiffness coefficient $\bar{S}_{D}$ with thickness ratio $r_{b}$ for different values of $\alpha$ 
Figure 5 shows the variation of dimensionless dynamic damping coefficient $\bar{C}_{D}$ with respect to the film thickness ratio $r_{b}$ for different values of curvature parameter $\Delta$ and pseudoplasticity parameter $\alpha$. The coefficient of damping is observed to decrease with the increase in the thickness ratio $r_{b}$. Also, for each value of $r_{b}$, the coefficient of damping for $\alpha=-0.1$ is higher than that for $\alpha=0$ and for $\alpha=0.1$, it is less than that in the case of $\alpha=0$. Therefore, on comparison with the Newtonian case, the effect of dilatant fluid increases the value of damping coefficient and hence enhances the load capacity, whereas, pseudoplasticity decreases the value of damping coefficient. Also, the effect of non-Newtonian (pseudoplastic and dilatant) lubricant on damping coefficient is significant with $r_{b}>1.5$ : showing an agreement with the result of load capacity discussed in Figure 4.

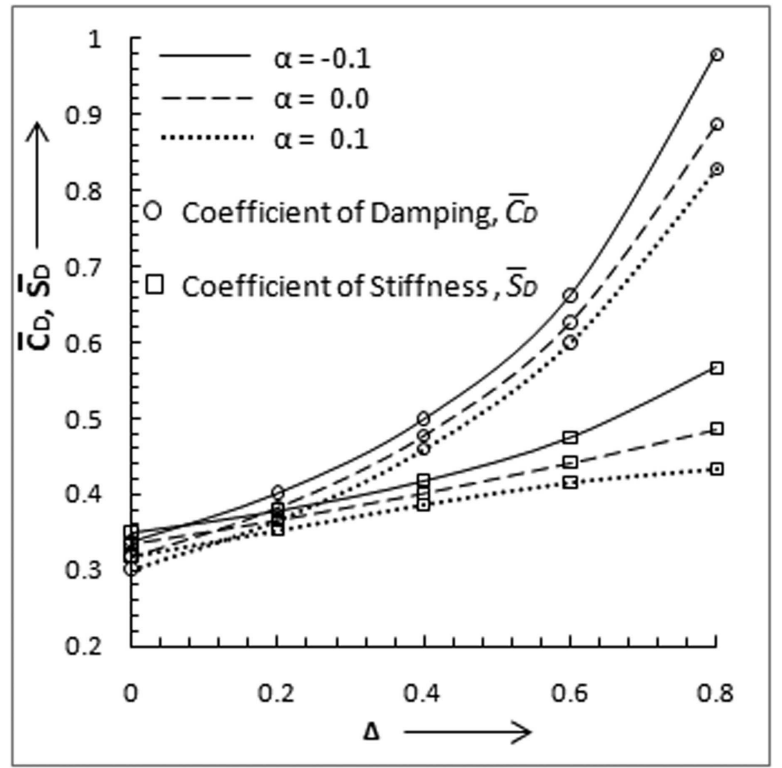

Fig. 7. Variation of dimensionless coefficients of stiffness and damping $\bar{S}_{D}, \bar{C}_{D}$ with $\Delta$ thickness for ratio $r_{b}=2$

Figure 6 shows the variation of dynamic stiffness coefficient $\bar{S}_{D}$ of bearing with respect to the step ratio $r_{b}$ with different values of curvature parameter $\Delta$ and pseudoplasticity parameter $\alpha$. The dynamic stiffness coefficient $\bar{S}_{D}$ is observed to increase with the increase in the step ratio $r_{b}$ upto $r_{b} \approx 2$ and decrease thereafter for each $\Delta$. It is clearly observed that for each value of $\Delta$ and $r_{b}$, the stiffness coefficient $\bar{S}_{D}$ for $\alpha=-0.1$ (dilatant lubricants) is higher than Newtonian case $(\alpha=0)$ and for $\alpha=0.1$ (pseudoplastic lubricants), it is less than Newtonian case. Further, a difference in stiffness coefficient due to non-Newtonian (pseudoplastic and dilatant) effects is clearly observed for $r_{b}>1.5$ and the stiffness coefficient with pseudoplasticity as well as dilatant 
fluid is of almost same order as in Newtonian case for $r_{b}<1.5$. Thus, the dilatant lubricants significantly increase the life of bearing for $r_{b}>1.5$ and for the pseudoplastic lubricants, the case is reversed.

Figure 7 shows the variation of dimensionless dynamic damping coefficient $\bar{C}_{D}$ and dynamic stiffness coefficient $\bar{S}_{D}$ with respect to the slider curvature parameter $\Delta$ for different values of pseudoplasticity parameter $\alpha$ with step ratio $r_{b}=2$. Both the coefficients of damping and stiffness show an increase with the increase in $\Delta$. Further, for each value of $\Delta$, both the coefficients of damping and stiffness for $\alpha=-0.1$ (dilatant lubricants) is higher than the Newtonian case $(\alpha=0)$ and for $\alpha=0.1$ (pseudoplastic lubricant), it is smaller than the Newtonian case.

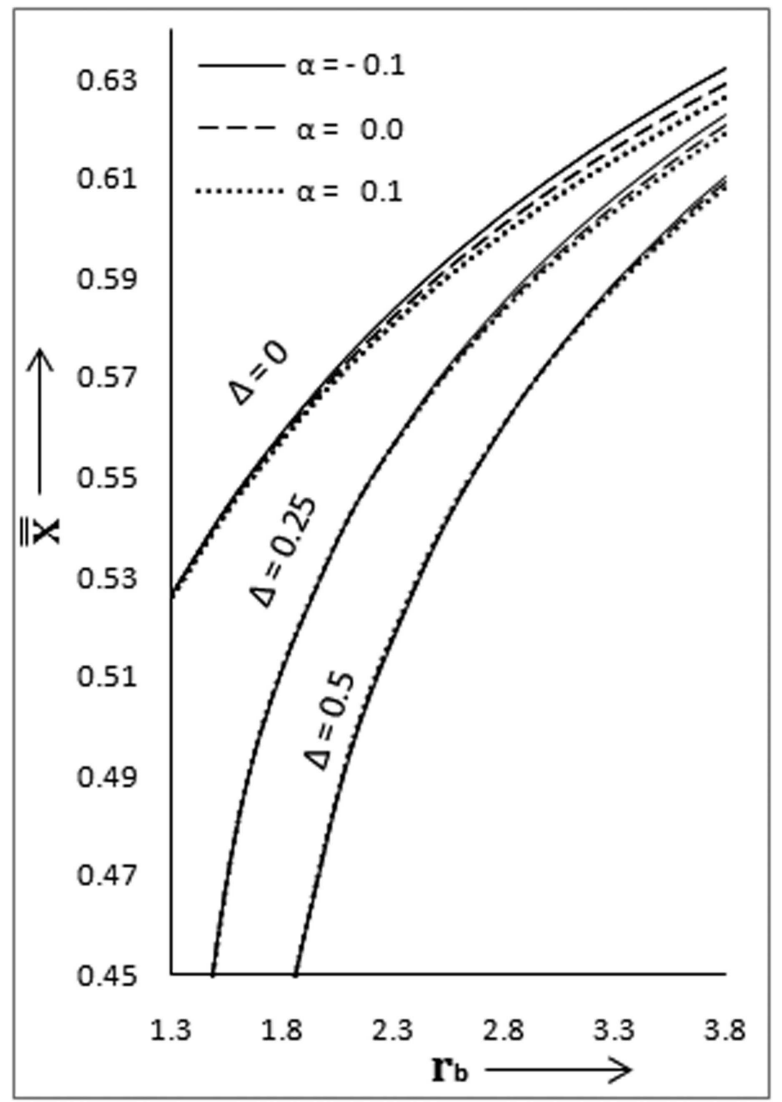

Fig. 8. Variation of dimensionless centre of pressure of bearing ( $\overline{\bar{x}})$ with $r_{b}$. Newtonian results are identical with Kapur [20]

Thus, the effect of increasing the curvature, as well as dilatant lubricant, is observed to increase the pressure and load capacity. Further, increase in dynamic damping enhances the bearing stability and hence its performance 


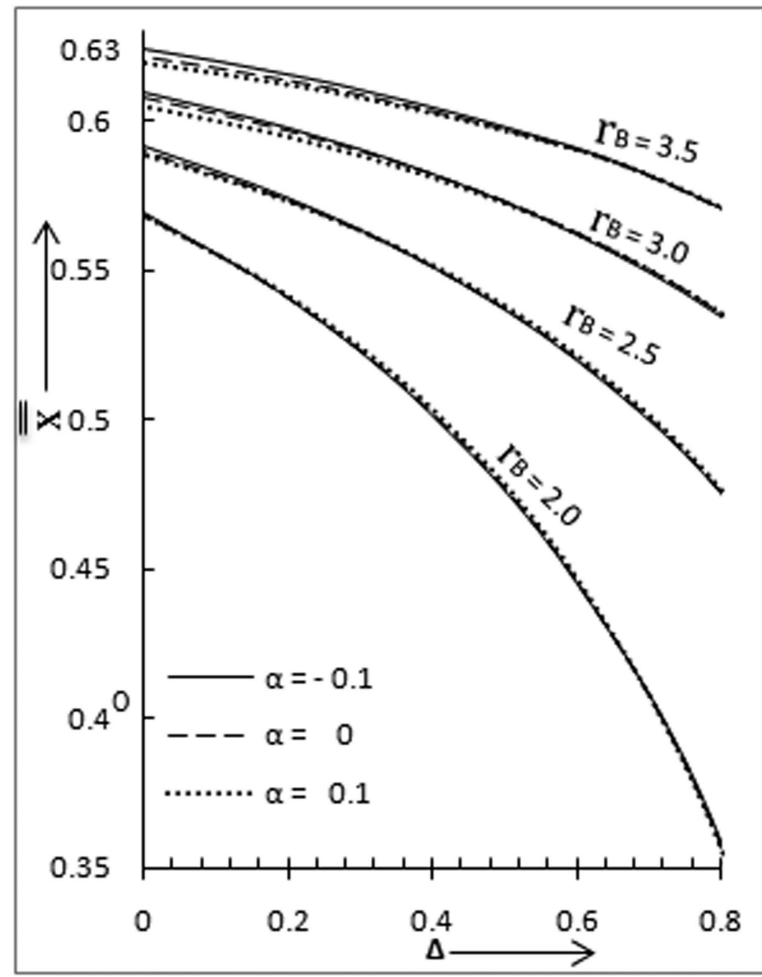

Fig. 9. Percentage variation of dimensionless centre of pressure of bearing with $\Delta$. Newtonian results are identical with Kapur [20]

and increase in the dynamic stiffness of the bearing increases the bearing life due to its property. The results of pseudoplasticity indicate towards the instability and shorter bearing life.

Figure 8 shows the variation of dimensionless centre of pressure $\overline{\bar{x}}$ with respect to $r_{b}\left(1.3<r_{b}<3.8\right)$ for curvature parameter $\Delta=0,0.25,0.5$ with different values of parameter of pseudoplasticity $\alpha$. It is observed that the centre of pressure moves towards the outlet of the bearing with increase of $r_{b}$. Also, it is clear from the figure that the relative movement of centre of pressure is enhanced with the increase of $\Delta$. Further, for each $\Delta$, the plot of centre of pressure with $\alpha=-0.1$ (dilatant lubricant) is above the Newtonian plot $(\alpha=0)$ and for $\alpha=0.1$ (pseudoplastic lubricant), it is below Newtonian plot i.e. on comparison with the Newtonian case, a shift of the centre of pressure towards the inlet of the bearing is observed with the pseudoplastic lubricants and a shift of the centre of pressure towards the outlet of the bearing is observed with the dilatant lubricants. However, the effect of Non-Newtonian (pseudoplastic and dilatant) lubricant on centre of pressure is observed significant in the case of plane slider and it decreases 
with the increase of curvature parameter $\Delta$. Thus, the effect of curvature is analyzed to stabilize the centre of pressure over the lubricant effects.

Figure 9 shows the variation of dimensionless centre of pressure $\overline{\bar{x}}$ with respect to the curvature parameter $\Delta$ for different values of $\alpha$ and $r_{b}$. It is observed that, on increasing the slider curvature $\Delta$, the centre of pressure shifts towards the inlet of the bearing for each value of $r_{b}$ and each value of $\alpha$. The change of centre of pressure due Non-Newtonian (pseudoplastic and dilatant) effect is observed to be significant for $\Delta \leq 0.2$ and $r_{b} \geq 3$ and for this range of parameters, the centre of pressure moves towards the inlet with the pseudoplastic fluids and towards the outlet with the dilatant fluids. It is clearly observed from the figure that for $r_{b}<3$, the centre of pressure is not much affected due to the Non-Newtonian (pseudoplastic and dilatant) lubricants regardless of the curvature. Again, for $\Delta>0.3$, the stability of centre of pressure is not affected due to lubricants regardless of the value of step ratior $r_{b}$.

Therefore, it is concluded that with a suitable choice of design parameters $\Delta>0.2$ and $2<r_{b}<3$, the effect of non-Newtonian (pseudoplastic and dilatant) lubricants on the shift of centre of pressure can be avoided, and stability of the centre of pressure and hence the stability of the bearing can be improved.

\section{Conclusion}

We have presented the effects of isothermal incompressible non-Newtonian pseudoplastic and dilatant lubricants on the steady and dynamic characteristics of one-dimensional pivoted curved slider bearings, neglecting the effects of fluid inertia and cavitation.

For the Rabinowitsch fluid model, the modified Reynolds equation considering transient motion of the slider is derived. Further, the modified Reynolds equations for the steady state and damping conditions have been obtained.

To obtain the steady and dynamic characteristics of the bearing, the two modified Reynolds equations have been solved using small perturbation technique. The results are in well agreement with the Newtonian results for the parameter of pseudoplasticity $\alpha=0$.

The steady pressure and steady load, dynamic damping and dynamic stiffness as well as the centre of pressure and hence the bearing stability, performance and life depend upon the coefficient of pseudoplasticity $\alpha$, step ratio $r_{b}$ and curvature $\Delta$.

Based on the results, so obtained, the following conclusions have been drawn: 
1. Steady state pressure and load capacity increases significantly with the dilatant lubricants and curvature, and decreases with the pseudoplastic lubricants.

2. Dynamic damping and dynamic stiffness of bearing significantly increase with the dilatant lubricant as well as the curvature and hence enhances the stability and life of the bearing but the case is reversed for the pseudoplastic lubricants.

3. The steady state load capacity and dynamic stiffness increases with $r_{b}$ upto $r_{b} \approx 2$ and decreases thereafter while the dynamic damping decreases with the increase of $r_{b}$.

4. An indication of small and less significant non-Newtonian effects on steady and dynamic characteristics is observed for $r_{b}<1.7$.

5. The centre of pressure moves towards the bearing inlet with the increase of curvature $\Delta$, and it moves towards the outlet with increase of step ratio $r_{b}$.

6. The pseudoplastic lubricants shift the centre of pressure towards bearing inlet while the dilatants shift it towards outlet. However, with the suitable choice of design parameters $\Delta>0.2$ and $2<r_{b}<3$, shift of centre of pressure becomes almost negligible of the non-Newtonian effects.

\section{Appendix}

In absence of external body forces, the Navier-Stokes equations for incompressible fluids is expressed in Cartesian coordinate system as :

$$
\begin{aligned}
& \rho\left(u \frac{\partial u}{\partial x}+v \frac{\partial u}{\partial y}+w \frac{\partial u}{\partial z}\right)=-\frac{\partial p}{\partial x}+\left(\frac{\partial \tau_{x x}}{\partial x}+\frac{\partial \tau_{x y}}{\partial y}+\frac{\partial \tau_{x z}}{\partial z}\right) \\
& \rho\left(u \frac{\partial v}{\partial x}+v \frac{\partial v}{\partial y}+w \frac{\partial v}{\partial z}\right)=-\frac{\partial p}{\partial y}+\left(\frac{\partial \tau_{y x}}{\partial x}+\frac{\partial \tau_{y y}}{\partial y}+\frac{\partial \tau_{y z}}{\partial z}\right) \\
& \rho\left(u \frac{\partial w}{\partial x}+v \frac{\partial w}{\partial y}+w \frac{\partial w}{\partial z}\right)=-\frac{\partial p}{\partial z}+\left(\frac{\partial \tau_{z x}}{\partial x}+\frac{\partial \tau_{z y}}{\partial y}+\frac{\partial \tau_{z z}}{\partial z}\right)
\end{aligned}
$$

and the equation of continuity is expressed as

$$
\frac{\partial u}{\partial x}+\frac{\partial v}{\partial y}+\frac{\partial w}{\partial z}=0
$$

The necessary assumptions for thin film lubrication $[18,23]$ can be summarized as :

1. Laminar flow condition prevails.

2. Fluid is incompressible. 
4. No variation of pressure across the fluid film (i.e. $\frac{\partial p}{\partial y}=0$ ).

5. Inertia forces resulting from acceleration of fluid particles are small as compared to viscous forces and are negligible.

6. All velocity gradients are negligible in comparison to the transverse velocity gradients i.e. $\frac{\partial}{\partial x}, \frac{\partial}{\partial z} \ll \frac{\partial}{\partial y}$.

7. No slip condition prevails at the bearing surfaces.

8. Heat conduction and convection effects have been neglected.

9. Effects of material properties such as porosity, hardness of material have been neglected.

10. Length of slider is as long in comparison to its width as it can be treated infinite without a loss of generality.

Under these assumptions, momentum equations (36-38) for one dimensional flow (i.e. $v=0$ ) can be re-written as

$$
\begin{gathered}
0=-\frac{\partial p}{\partial x}+\frac{\partial \tau_{x y}}{\partial y} \\
0=\frac{\partial p}{\partial y}
\end{gathered}
$$

and the equations of continuity (39), in this case, can be represented as

$$
\frac{\partial u}{\partial x}+\frac{\partial w}{\partial y}=0
$$

where, the constitutive equation is given by the Rabinowitsch relation, equation (1).

\section{Nomenclature}

$\begin{array}{lll}h & : & \text { Film thickness, } \\ B & : & \text { Length of bearing, } \\ L & : & \text { Width of bearing, } \\ t & : & \text { Time, } \\ h_{s}(x) & : & \text { Steady state film thickness, } \\ h_{m}(t) & : & \text { Variation of film thickness with time, } \\ h_{1} & : & \text { Outlet film thickness, } \\ h_{2} & : & \text { Inlet film thickness, } \\ H_{c} & : & \text { Height of crown segment of slider, } \\ u & : & \text { Velocity in X-direction, }\end{array}$


$v$

$\omega$

$\tau_{x y}$

$p$

$W$

$F_{D}$

$S_{D}$

$C_{D}$

$\mu$

$\kappa$

$r_{b}$

$\bar{x}$

$\bar{h}$

$\bar{h}_{m}$

$\bar{h}_{s}$

$\bar{p}$

$\alpha$

$\vartheta$

$\Delta$

$\tau$

$\varepsilon$

$\bar{F}_{D}$

$\bar{C}_{D}$

$\bar{S}_{D}$

$\bar{W}$
Velocity in Y-direction,

Frequency of oscillation,

Shearing stress,

Film pressure,

Load carrying capacity of film,

Film force,

Dynamic stiffness coefficient,

Dynamic damping coefficient,

: Zero shear rate viscosity,

: coefficient of Pseudoplasticity,

: $\quad$ Step ratio $h_{2} / h_{1}$,

$: \quad x / B$,

$: \quad h / h_{1}$,

$: \quad h_{m} / h_{1}$

$: \quad h_{s} / h_{1}$,

$: \quad h_{1}^{2} p / \mu U B$

: $\quad \kappa \mu^{2} U^{2} / h_{1}^{2}$,

: $B \omega / U$,

: $H_{c} / h_{1}$,

: $t \omega$,

: Small amplitude of oscillation,

: $\quad h_{1}^{2} F_{D} / \mu U L B^{2}$

$: \quad h_{1}^{3} C_{D} / \mu L B^{3}$,

$: \quad h_{1}^{3} S_{D} / \mu U L B^{2}$ and

: $\quad W h_{1}^{2} / \mu U L B^{2}$.

Manuscript received by Editorial Board, September 09, 2011; final version, March 30, 2013.

\section{REFERENCES}

[1] Spikes H.A.: 1994. The Behaviour of Lubricants in Contacts: Current Understanding and Future Possibility. IMechE J. Eng. Tribol., Vol. 208, pp. 3-7.

[2] Brunstrum L.C., and Leet R.H.: 1956. Capillary Viscometry of Lubricating Grease. Lubr. Eng., Vol. 12, pp. 316-325.

[3] Sisko A.W.: 1958. The Flow of Lubricating Greases. Ind. Eng. Chem., Vol. 50, pp. 1789-1792.

[4] Wada S., Hayashi H.: Hydrodynamic Lubrication of Journal Bearings by Pseudoplastic Lubricants. Bulletin of JSME 14, 1971, Vol. 69, pp. 279-286. 
[5] Bourgin P., Gay B.: Determination of the Load Capacity of Finite Width Journal Bearing by Finite Element Method in the Case of a Non-Newtonian Lubricant. ASME Journal of Tribology, 1984, Vol. 106, pp. 285-290.

[6] Hsu Y. C., Saibel E.: Slider Bearing Performance with a Non-Newtonian Lubricant. ASLE Trans. 8, 1965, pp. 191-194.

[7] Hashimoto H., Wada S.: The Effects of Fluid Inertia Forces in Parallel Circular Squeeze Film Bearing Lubricated with Pseudoplastic Fluids. ASME Journal of Tribology, 1986, Vol. 108, pp. 282-287.

[8] Usha R., Vimla P.: Fluid Inertia Effects in a Non-Newtonian Squeeze Film Between Two Plane Annuli. Transaction of ASME, 2000, vol. 122, pp. 872-875.

[9] Hung C. R.: Effects of Non-Newtonian Cubic-Stress Flow on the Characteristics of Squeeze Film Between Parallel Plates. Education Specialization 97P, 2009, pp. 87-97.

[10] Singh U.P., Gupta R.S., and Kapur V.K.: On the Steady Performance of Hydrostatic Thrust Bearing: Rabinowitsch Fluid Model. Tribology Transactions, 2011, Vol. 54, pp. 723-729.

[11] Singh U.P., Gupta R.S., and Kapur V.K.: Effects of Inertia in the Steady State Pressurised Flow of a non-Newtonian Fluid Between two Curvilinear Surfaces of Revolution: Rabinowitsch fluid model. Chemical and Process Engineering, 2011, Vol. 32, Issue 4, pp. 333-349.

[12] Singh U.P., Gupta R.S., and Kapur V.K.: On the Steady Performance of Annular Hydrostatic Thrust Bearing: Rabinowitsch fluid model. ASME Journal of Tribology, 2012, Vol. 134, Issue 4, pp. 1-5.

[13] Singh U.P., Gupta R.S., and Kapur V.K.: On the Squeeze Film Characteristics Between a Long Cylinder and a Flat Plate: Rabinowitsch fluid model. Journal of Engineering Tribology - Proc. Inst. Mech. Engrs. London. DOI: 10.1177/1350650112458742.

[14] Sharma R. K., Pandey R. K.: An investigation into the Validity of the Temperature Profile Approximations across the Film Thickness in THD Analysis of Infinitely Wide Slider Bearing. Tribology Online, 2006, Vol. 1, No. 1, pp. 19-24.

[15] Gautam S. S.: An Approach To Calculate Leakage Flow, Stiffness And Damping Of Annular Seals In Turbulent Flow Using Lubrication Theory, Part II : Results. Tribology Online, 2007, Vol. 2, No. 4, pp. 99-104.

[16] Tsuchiama R., Honchi M., Xu J.: An Analytic Model of Contact Vibration of Slider. Tribology Online, 2008, Vol. 3, No. 6, pp. 316-321.

[17] Gautam S. S., Meena L., Gosh M. K.: Dynamic Characteristics and Stability of Short Wave Journal Bearings. Tribology Online, 2010, Vol. 5, No. 2, pp. 92-95.

[18] Pinkus O., and Sternlicht B.: Theory of hydrodynamic lubrication. McGraw Hill, New York, 1961.

[19] Abramovitz S.: Theory for a Slider Bearing with a Convex Pad Surface; Side Flow Neglected. Journal of the Franklin Institute, 1955, Vol. 259, No. 3, pp. 221-233.

[20] Kapur V. K.: Magneto-Hydrodynamic Pivoted Slider Bearing with a Convex Pad Surface. Japanese Journal of Applied Physics, 1969, Vol. 8, No. 7, pp. 827-833.

[21] Naduvinamani N. B., Marali G. B.: Dynamic Reynolds Equation for Micropolar Fluid Lubrication of Porous Slider Bearings. Journal of Marine Science and Technology, 2008, Vol. 16, No. 3, pp. 182-190.

[22] Taylor C.M., and Dowson D.: Turbulent Lubrication Theory-Application to Design. J. Lubr. Tech., 1974, Vol. 96, No. 1, pp. 36-47.

[23] Cameron A.: Basic lubrication theory. Ellis Horwood, Chichester, 1976. 


\section{Zastosowanie modelu płynu Rabinowitch’a do uchylnych, łożysk ślizgowych z zakrzywionym ślizgaczem}

\section{Streszczenie}

W przedstawionej analizie teoretycznej badano, przy wykorzystaniu modelu płynu Rabinowitch’a, łączny wpływ krzywizny ślizgacza i smaru o właściwościach pseudoplastycznych, nieniutonowskich, o odwróconej plastyczności (smar zmieszany ze środkiem poprawiającym wskaźnik lepkości) na charakterystyki w stanie ustalonym i warunkach dynamicznych uchylnego, łożyska ślizgowego. Zmodyfikowane równania Reynoldsa otrzymano dla stanów ustalonych i tłumionych łożyska. W celu rozwiązania zmodyfikowanych równań Reynoldsa zastosowano teorię perturbacji. Wielkości charakterystyczne dla stanu ustalonego (ciśnienie smaru w stanie ustalonym, nośność i środek ciśnienia) i charakterystyki dynamiczne (tłumienie dynamiczne i sztywność dynamiczna) zostały wyznaczone numerycznie, przy użyciu pakietu Mathematica, dla różnych wartości wskaźnika poprawy lepkości. W porównaniu ze smarami o właściwościach cieczy newtonowskiej, dla smaru o odwróconej plastyczności uzyskano wyższe wartości ciśnienia w filmie, większą nośność, lepsze tłumienie dynamiczne i dynamiczną sztywność. Sytuacja wyglądała odwrotnie w przypadku smarów pseudoplastycznych. Znaczące zmiany charakterystyk łożyska, związane z nie-newtonowskim, pseudoplastycznym zachowaniem płynu o odwróconej plastyczności, zaobserwowano już przy małych wartościach parametru pseudoplastyczności. 